\title{
Médiévales
}

Langues, Textes, Histoire

60 | printemps 2011

La fitna

\section{Minorités et régulations sociales en Méditerranée médiévale}

Actes du colloque réuni du 7 au 9 juin 2007 en l'Abbaye royale de Fontevraud (Maine-et-Loire), sous la direction de Stéphane BOISSELLIER, François CLÉMENT et John TOLAN, Rennes, Presses universitaires de Rennes, 2010, 349 p. (Collection Histoire)

\section{OpenEdition \\ Journals}

Édition électronique

URL : https://journals.openedition.org/medievales/6239

DOI : 10.4000/medievales.6239

ISSN : $1777-5892$

\section{Éditeur}

Presses universitaires de Vincennes

\section{Édition imprimée}

Date de publication : 30 juin 2011

Pagination : 217-218

ISBN : 978-2-84292-273-3

ISSN : 0751-2708

Référence électronique

"Minorités et régulations sociales en Méditerranée médiévale », Médiévales [En ligne], 60 | printemps 2011, mis en ligne le 30 août 2011, consulté le 24 avril 2022. URL : http://journals.openedition.org/ medievales/6239; DOI : https://doi.org/10.4000/medievales.6239

Ce document a été généré automatiquement le 24 avril 2022

Tous droits réservés 


\section{Minorités et régulations sociales en Méditerranée médiévale}

Actes du colloque réuni du 7 au 9 juin 2007 en l'Abbaye royale de Fontevraud (Maine-et-Loire), sous la direction de Stéphane BOISSELLIER, François CLÉMENT et John TOLAN, Rennes, Presses universitaires de Rennes, 2010, 349 p. (Collection Histoire)

1 Monique Bourin, Préface, p. 7-12. - Introduction. Stéphane Boissellier, «De la différenciation sociale à la minoration en passant par les régulations, quelques propositions ", p. 15-48.

Première partie. Vivre sa différence, de la marginalité à la minorité. - François Clément, "Les homosexuels dans l'Occident musulman médiéval: peut-on parler de minorité ?», p. 51-72 - Stéphane Boissellier, «La définition de la minorité féminine dans la paysannerie, normes et usages (Portugal, $\mathrm{XII}^{\mathrm{e}}-\mathrm{XV}^{\mathrm{e}}$ siècle) », p. 73-95- Bernardo Vasconcelos e Sousa, "Pauvres, charité et assistance au Portugal (XIV $-\mathrm{XV}^{\mathrm{e}}$ siècle) », p. 97-106 - Paul Freedman, « Serfs as a Medieval Minority », p. 107-122.

Deuxième partie. Minorités de pouvoir, minorités au pouvoir. - Sylvie Denoix, « Construction sociale et rapport à la norme d'un groupe minoritaire dominant: les Mamlouks (1250-1517)», p. 125-144 - Ana Echevarria Arsuaga, «Entre minorité de fonction et minorité dominante: le cas des musulmans castillans ", p. 145-160Philippe Josserand, « Nuestro moro que tiene a Cervera : un châtelain musulman au service de l'ordre de l'Hôpital au début du XIV e siècle », p. 161-177.

Troisième partie. Voyageurs, mercenaires et captifs, des minorités de fortune. Pierre Moukarzel, «Les marchands européens dans l'espace urbain mamelouk: un groupe minoritaire privilégié ?», p. 181-205 - Abdellatif Ghouirgate, "Les Maghrébins au Proche-Orient: une minorité visible?», p. 207-221-John Tolan, «Marchands, mercenaires et captifs: le statut légal des chrétiens latins en terre d'islam selon le juriste canonique Ramon de Penyafort (XIII ${ }^{\mathrm{e}}$ siècle) », p. 223-234.

5 Quatrième partie. Minorités et contre-culture. - Juliette Sibon, « La minorité juive dans l'environnement urbain à Marseille au XIVe siècle », p. 237-250 - Thomas Deswarte, 
"Une minorité chrétienne en Occident : la Chrétienté hispanique et l'adoptianisme », p. 251-268 - R.I. Moore, « Popular heresy in mid-twelfth-century Italy », p. 269-279.

6 Cinquième partie. Les minorités au miroir de la culture dominante. - Charles Garcia, «La minorité 'franque' de Sahagún dans les Chroniques anonymes (xII siècle), p. 283-298 - Céline Pérol, «Les magnats florentins ou la construction d'une minorité dangereuse », p. 299-316 - Damian Smith, « Religious minorities viewed from Rome : the papacy and the heretics ", p. 317-329.

7 Conclusions. - Martin Aurell, « La remise en question d'un concept », p. 333-343.

8 Les auteurs, p. 345. 